\title{
Violencia política, dictadura militar y memoria. La Argentina de los años setenta y ochenta a partir del Archivo Marshall T. Meyer
}

\author{
Violência política, ditadura militar e memória. \\ A Argentina dos anos setenta e oitenta a partir do Arquivo Marshall T. Meyer \\ Political Violence, Military Dictatorship, and Memory. \\ The Argentina of the Seventies and Eighties from the Marshall T. Meyer Archive
}

Sebastián Carassai*

\begin{abstract}
Resumen: El rabino norteamericano Marshall T. Meyer fue una figura destacada de la colectividad judía argentina y un pionero defensor de los derechos humanos durante la última dictadura militar (1976-1983). En años recientes, su archivo personal ha sido incorporado al Archivo de Derechos Humanos de la David M. Rubenstein Library, la Biblioteca de Manuscritos y Libros Raros de la Universidad de Duke. A partir de sus sermones, discursos, correspondencia personal y profesional, escritos, entrevistas y material audiovisual, este trabajo reconstruye su trayectoria en Argentina, deteniéndose específicamente en los años de la radicalización política, la represión, y los primeros años de la post-dictadura. El artículo comienza con el arribo de Meyer a la Argentina, en el año 1959, describe su impresión acerca de la sociedad que lo recibió y la relación entre sociedad y judaísmo que buscó imprimir en sus instituciones. Luego se centra en su percepción acerca del peronismo, la violencia política que caracterizó a la primera mitad de la década del setenta, el compromiso que asumió con los derechos humanos en la segunda mitad y, finalmente, la construcción de una primera memoria, en los años ochenta, sobre la dictadura que comenzaba a dejarse atrás. El camino así trazado abre un registro íntimo, individual y por momentos también comunitario, de los años de la violencia política, la dictadura militar y la transición a la democracia.
\end{abstract}

Palabras clave: Violencia política; Represión; Dictadura militar; Memoria; Rabino Marshall T. Meyer.

\begin{abstract}
Resumo: O rabino norte-americano Marshall Meyer foi uma figura destacada da comunidade judaica-argentina e um defensor pioneiro dos direitos humanos durante a última ditadura militar (1976-1983). Nos últimos anos, seu arquivo pessoal foi incorporado ao Arquivo de Direitos Humanos da David M. Rubenstein Library, a Biblioteca de Manuscritos e Livros Raros da Universidade de Duke. A partir de seus sermões, discursos, correspondências pessoais e profissionais, escritos, entrevistas e material áudio-visual, este trabalho reconstrói sua trajetória na Argentina, focando especificamente nos anos de radicalização política, na repressão, e nos primeiros anos pós-ditadura. O artigo começa com a chegada de Meyer à Argentina, no ano de 1959, descrevendo sua impressão sobre a sociedade que o recebeu e a relação entre sociedade e judaísmo que buscou imprimir em suas instituições. Logo, se centra em sua percepção em relação ao peronismo, na violência política que caracterizou a primeira metade da década de setenta, no compromisso que assumiu com os direitos humanos na segunda metade e, finalmente, na construção de uma primeira memória, nos anos oitenta, sobre a ditadura que começava a ficar no passado. O caminho assim traçado abre um registro íntimo, individual e em alguns momentos também comunitário, dos anos de violência política, ditadura militar e a transição à democracia.
\end{abstract}

Palavras-chaves: Violência política; Repressão; Ditadura militar; Memória; Rabino Marshall T. Meyer.

\footnotetext{
* Profesor universitario (Universidad de Buenos Aires) e investigador adjunto en el Consejo de Investigaciones Científicas y Técnicas (CONICET) dados biográficos_biographic data
} 


\begin{abstract}
The North American Rabbi Marshall Meyer was a leading figure of the Jewish-Argentine community and a pioneering advocate for human rights during the last military dictatorship (1976-1983). In recent years, his personal archive has been incorporated into the Human Rights Archive of the David M. Rubenstein Library, the Manuscripts and Rare Books Library of Duke University. From his sermons, speeches, personal and professional correspondence, essays, interviews, and audiovisual material, this work reconstructs his trajectory in Argentina, focusing specifically on the years of political radicalization, repression, and the years just after the dictatorship. The article begins with the arrival of Meyer to Argentina in 1959, describing his impression of the society that welcomed him and the relation between this society and the Judaism that he sought to instill in his institutions. Later, he focuses on his perception of Peronism, the political violence that characterized the first half of the seventies, the commitment he made with the struggle for human rights in the second half and, finally, the construction of a first memory, in the eighties, of the dictatorship that was being left behind. An inquiry into Meyer's life opens up an intimate registry, individual and oftentimes communal, of the years of political violence, military dictatorship, and the transition to democracy.
\end{abstract}

Keywords: Political violence; Repression; Military dictatorship; Memory; Marshall T. Meyer Rabbi.

\section{Introducción}

El rabino norteamericano Marshall T. Meyer constituye una figura icónica para los argentinos sensibles a las causas de derechos humanos. Educado en el Dartmouth College y en el Jewish Theological Seminary of America, llegó a Buenos Aires en el año 1959, contratado por la Congregación Israelita de la República Argentina (CIRA) para trabajar junto al Gran Rabino Guillermo Schlesinger. A los pocos años, sin embargo, decidió hacer su propio camino y revitalizar un judaísmo que juzgaba dormido no sólo en el país sino también en toda Latinoamérica. A comienzos de los años sesenta creó dos instituciones, el Seminario Rabínico Latinoamericano y la sinagoga Bet El, cuyo liderazgo ejerció hasta su regreso a los Estados Unidos, en 1984. Por su compromiso en la defensa de las víctimas de la represión ilegal durante los años de la última dictadura militar (1976-1983), el presidente Raúl Alfonsín lo convocó a formar parte de la Comisión Nacional sobre la Desaparición de Personas (CONADEP) y su gobierno lo condecoró con la Orden del Libertador San Martín en el grado de Comendador.

La colección de documentos personales de Marshall T. Meyer, desde hace unos pocos años accesible en el Archivo de Derechos Humanos de la David M. Rubenstein Library, Biblioteca de Manuscritos y Libros Raros de la Universidad de Duke, abre un sendero alternativo para considerar los años de la violencia política y el terrorismo de Estado en Argentina, así como también los de la formación de una temprana memoria sobre el último. ${ }^{1}$ Esa colección reúne un

\footnotetext{
1 Debo a mi colega y amiga Deborah Jakubs, vice rectora de Asuntos Bibliotecarios de la Universidad de Duke, la invitación a consultar este archivo, a ella y Gilbert Merkx, director del Área de Estudios Internacionales de esa universidad, el apoyo y la
}

valioso acervo documental compuesto por sermones, discursos, correspondencia personal y profesional, escritos, entrevistas y material audiovisual, en conjunto poco explorado hasta la actualidad. ${ }^{2}$ Los trabajos destinados al análisis de la comunidad judía durante los años setenta se centran en el rol de las organizaciones judías y sus dirigencias, el antisemitismo, la política del Estado de Israel y sus vínculos con el régimen militar argentino, o en casos particulares como el de Jacobo Timerman (SENKMAN, 1986; WAISMAN, 1987; ZOHAR, 1991; SENKMAN y SZNAJDER, 1995; MOCHKOSFKY, 2004; LOTERSZTAIN, 2008; KAHAN, 2015; y SCHENQUER, 2016, entre otros). Por otra parte, los textos abocados a la figura del rabino Marshall Meyer se focalizan en su biografía intelectual, el carácter heroico de su comportamiento durante los años del terrorismo de Estado o en la relevancia de sus enseñanzas religiosas (PLAVNIK, 1989; MEYER, 2004; VOLCOVICH, 2009; ROSEMBERG, 2010; y FAINSTEIN, 2013). En este trabajo me propongo, en cambio, reconstruir las percepciones que de la sociedad argentina fue forjándose el rabino Meyer, las tensiones que atravesaron a su comunidad durante

generosidad con que me recibieron en el invierno de 2015 en Carolina del Norte y al CONICET el financiamiento de mi estadía en los Estados Unidos. A Eric Meyers en Durham, a Bob Cox en Charleston, y Naomi Meyer y al rabino Rolando Matalon, en New York, les agradezco las entrevistas que me concedieron en distintos momentos de 2015 y 2016. Cox y Meyer, además, pusieron a mi disposición sus archivos personales. Una versión preliminar de este trabajo fue presentada en la "International Studies Conference on the Politics of Memory", en la Universidad de Kentucky, el 13 de marzo de 2015. Gracias a los colegas que participaron de esa conferencia, a Janaina Martins Cordeiro y Lívia Gonçalves Magalhães, que me invitaron a participar del este dossier, y a los comentaristas de la revista.

2 Todas las citas a pie de página en las que se indica número de caja $\left(\right.$ Box N $\left.^{\circ}\right)$ pertenecen a la Marshall T. Meyer Papers Collection, Human Rights Archive, David M. Rubenstein Rare Book \& Manuscript Library, Duke University. 
los años setenta, y finalmente el nacimiento de una temprana memoria acerca de la historia reciente argentina. El análisis de los documentos que el rabino norteamericano conservó, tanto de aquellos que refieren exclusivamente a su persona como de los que atañen a algunos problemas en su comunidad, brinda acceso a un registro íntimo, individual y por momentos también comunitario, de los años de la violencia política, la dictadura y la transición a la democracia.

\section{Los primeros años en Argentina: entre la fascinación y el desconcierto}

Las primeras cartas que Marshall Meyer escribió desde Argentina a sus amigos y familiares en los Estados Unidos combinaron fascinación y desconcierto. Meyer estaba fascinado por el charm parisino de la ciudad de Buenos Aires, su Teatro Colón, "la segunda casa de ópera más grande del mundo, donde iremos el sábado por la noche a escuchar una actuación de Tosca" 3 y, hablando más en general, el hecho de que se tratara de una metrópolis con una relativamente refinada vida cultural. Estaba desconcertado, sin embargo, por el comportamiento de los porteños. "Una de las facetas más increíbles de la vida de esta ciudad", escribió Meyer poco después de llegar a Buenos Aires, "es que con toda esta gente y con un tráfico de vehículos tremendo, hay solamente un semáforo y ningún cartel de stop, lo que vuelve necesaria una rápida oración, un cierre de ojos, la esperanza de que suceda lo mejor, y una carrera hacia el otro lado de la calle". ${ }^{4}$ Como se verá más adelante, Meyer nunca abandonó del todo esta percepción mixta de la sociedad que lo recibió, tan sofisticada en algunos aspectos como primitiva en otros.

En su primer sermón en castellano para el día de Shabbat Shuvah [Shabat de retorno] en la CIRA, Meyer reflexionó sobre la situación geopolítica mundial, el progreso de la ciencia y el rol de la humanidad frente a ambos. "Nuestro mundo está dividido en dos campos armados y la centralización del poder en Washington y en Moscú es un horrendo espectro en el horizonte del mundo político", dijo en un sermón que combinaba política internacional y espiritualidad judía. ${ }^{5}$ "Ante la arremetida del progreso de la ciencia que avanza

\footnotetext{
3 Meyer era un apasionado conocedor de ópera. Sobre los años previos a su arribo a Argentina, véase FAINSTEIN, 2013, 41-82.

4 Las dos citas de este párrafo pertenecen a MEYER, Marshall. Carta a Henry y Becky Williams, 13 de agosto de 1959, Box 6, mi traducción.

5 Primer sermón en Buenos Aires, 1959, Box 8.
}

implacablemente", prosiguió, la humanidad se encuentra desamparada sin saber si será capaz "de asimilar o utilizar adecuadamente sus descubrimientos". Cuando pocos años después inaugure la sede de su Seminario Rabínico Latinoamericano, ante una audiencia encabezada por el vice-presidente de la nación, Carlos Perette, y el hermano del presidente, Ricardo Illia, Meyer presentará la nueva institución en contraste con ese mundo impiadoso en medio del cual ella debía abrirse camino. ${ }^{6}$ Luego de describir extensamente, inspirado en Nietzsche, un sombrío panorama de la vida moderna en todas sus esferas (la sociedad, la política, la economía, la ciencia, la educación, el arte, la religión, la filosofía y la moral), subrayó que el novel seminario nacía en "ese mundo nublado y confuso". "Estamos ebrios con nuestra riqueza, con nuestro poder, y con nuestro placer", agregó, y por ello las enseñanzas de la naciente institución debían proponerse "penetrar los huecos pechos de tantos hombres por doquier, porque lo que ha ido mal con nuestro mundo es que hemos cesado de escuchar la voz suave y pequeña del Dios viviente, creador del cielo y de la tierra". ${ }^{7}$ Dos años después, invitado a disertar por la Asociación Universitaria ArgentinoNorteamericana, pronunció una conferencia titulada "Crisis espiritual en América latina", en la que, además de resaltar la ausencia de espiritualidad, calificó de "confuso" y "peligroso" el "mundo en que vivimos". Como veremos, esta consternación que el curso del mundo moderno provocaba en Meyer colaboró a reforzar su misión religiosa.

Así, los años sesenta, tanto en Buenos Aires como en otras partes del mundo, fueron crecientemente percibidos por Meyer como un tiempo de "un rígido y frío materialismo" encarnado como nunca antes en "nuestros espíritus". La "cotidiana preocupación por la cuenta bancaria" o "la opulencia material" constituían para él un síntoma de "una aguda carencia de conciencia moral". ${ }^{9}$ De ahí la necesidad de encarar una labor de

\footnotetext{
6 "Funciona en Buenos Aires el primer seminario rabínico latinoamericano", Clarín, 13 de agosto de 1964.

7 MEYER, Marshall, Discurso en la inauguración de la sede del Seminario Rabínico Latinoamericano, noviembre de 1964, Box 8. Con otras palabras, dirá lo mismo en la reunión semanal del Rotary Club de Buenos Aires: "el hombre tiene la preocupación de la fábrica, del escritorio, de los negocios y se agobia por la repercusión de la bolsa y de la inflación; quisiera hablar de otra cosa y no puede". "Realizó ayer su reunión semanal el Rotary Club", La Prensa, 10 de marzo de 1966. Véase también "Problema espiritual del momento", Clarín, 10 de marzo de 1966.

8 "Sobre crisis espiritual en América latina se disertó", La Nación, 10 de septiembre de 1966; y "Crisis espiritual latinoamericana", Clarín, 10 de septiembre de 1966.

9 MEYER, Marshall. Primer sermón en Buenos Aires, 1959, Box 8.
} 
rehumanización que, partiendo de la comunidad judía, desbordara sus márgenes. La traducción institucional de esa labor derivó en la creación del seminario y en la fundación de una nueva comunidad, Bet El, en 1963. El seminario pronto se transformó en un propalador del judaísmo conservador en toda América latina. A diferencia del ortodoxo y del reformista, el judaísmo conservador considera a la religión como un proceso evolutivo. Nacido en Alemania en el año 1845, preserva de la tradición la esencia del mensaje judío pero la adapta a cada realidad social específica. ${ }^{10}$

En cuanto a la nueva comunidad judía, su relevancia se aprecia mejor si se atiende al contexto en el que Meyer impulsó su creación. A comienzos de los años sesenta en Argentina, la mayoría de las sinagogas imitaba el modelo de la nación originaria de sus fundadores, ya sea Marruecos, Alepo, Polonia, Rusia o Alemania. La segregación era tal que en muchos casos el casamiento entre un judío askenazí y otro sefardí era considerado un casamiento mixto. El proyecto de la comunidad Bet El, diría Meyer mucho después recordando su origen, obedeció al propósito de proveer al país la "primera sinagoga argentina", una que reflejara la realidad nacional. ${ }^{11}$ A diferencia de las otras sinagogas de comienzos de los años sesenta, en ella las prédicas eran siempre en castellano, había música en los servicios y los ritos askenazí y sefardí se amalgamaban. ${ }^{12}$

Luego de diez años en Argentina, Meyer comenzó a buscar otros horizontes. A mediados de 1969, escribió a su amigo Hyman Faine para comunicarle que estaba "más que seriamente considerando aliyah [emigrar a Israel]", voluntad que cifraba en su deseo de hacer una contribución no solamente para sino también desde ese país. ${ }^{13}$ Pidiendo expresa reserva, dado que ni en Bet

\footnotetext{
${ }^{10}$ Para algunos, esta terminología se adecuaba pobremente a la realidad latinoamericana. Meyer y otros rabinos cuestionaron su procedencia por considerar que conducía a equívocos políticos. Al respecto puede verse la carta que, desde el Seminario Rabínico Latinoamericano, el rabino Ángel Kreiman dirigió al rabino Richard Hirsh, presidente de la World Union for Progressive Judaism, insistiendo en la necesidad de abandonar estas denominaciones y estrechar lazos entre las así llamadas congregaciones reformistas y conservadoras que constituían la enorme mayoría del judaísmo latinoamericano. Carta de Ángel Kreiman a Richard Hirsh, sin fecha, Box 7. En 1962, además de la CIRA, adherían al movimiento conservador las sinagogas Nueva Comunidad Israelita y Congregación Lamrot-Hakol [A pesar de todo].

${ }^{11}$ MEYER, Marshall. Tercera conferencia en su visita a la argentina de 1986, Box 9.

${ }^{12}$ Sobre este punto véase el testimonio de Adolfo Sucari en VOLCOVICH, 2009.

${ }^{13}$ MEYER, Marshall. Carta a Hyman Faine, 13 de agosto de 1969, Box 6 , mi traducción.
}

El ni en el seminario estaban al tanto de sus deseos de aliyah, escribió varias cartas adjuntando su currículum vitae tanto a sus amigos Hyman y Ruth Faine como a distintas personalidades, entre ellas, Israel Goldstein, Moshe Davis y Abba Eban. ${ }^{14} \mathrm{~A}$ finales de ese mismo año viajó a Israel para tantear en primera persona las posibilidades efectivas de ocupar el Ministerio de Relaciones Exteriores o algún cargo oficial relacionado con las relaciones públicas y la imagen de Israel en el mundo. "He conocido un montón de embajadores de esta parte del mundo", escribió a su amigo Faine, "y discúlpame, pero pienso que yo podría hacer un mejor trabajo". ${ }^{15}$

Aunque pocas semanas después de esta correspondencia la revista judía $L a L u z$ lanzó una fuerte campaña contra Meyer, acusándolo de aprovechar sus campamentos juveniles para abusar sexualmente de sus discípulos, el deseo de abandonar Argentina no aparece en la correspondencia vinculado a este escándalo. ${ }^{16}$ En marzo de 1970, por otra parte, Meyer recibió un respaldo contundente de la Asamblea Rabínica norteamericana que desestimó dicha acusación, se negó a enviar un Bet Din [tribunal rabínico] a Buenos Aires, condenó a $L a L u z$ por haberse hecho eco de rumores que consideró infundados y encomendó darle toda la publicidad posible a esta notificación. ${ }^{17} \mathrm{Su}$ pretensión de abandonar Argentina aparece en su correspondencia asociada a tres motivos: su ya mencionado y recurrente deseo de aliyah, el temor a permanecer el resto de su vida en Buenos Aires (una idea que "no me hace muy feliz", como escribió a Faine), y la sensación de ya haber hecho suficiente en la que sería segunda patria.

En efecto, para 1969 Meyer había fundado el Seminario Rabínico para el subcontinente latinoamericano, una sinagoga y, junto a representantes de otras religiones, un ecuménico Instituto Superior de Estudios Religiosos. Además, había comenzado los campamentos juveniles Ramah, publicado la entera

\footnotetext{
${ }^{14}$ Israel Goldstein era un destacado rabino de New York, Moshe Davis uno de los maestros de Meyer y un prominente historiador del judaísmo norteamericano, y Abba Eban fue ministro de Relaciones Exteriores de Israel durante la Guerra de los Seis Días. Véase, como ejemplo, la carta de Meyer a Israel Goldstein, 13 de agosto de 1969, Box 6.

${ }^{15}$ MEYER, Marshall. Carta a Hyman Faine, 13 de agosto de 1969, Box 6, mi traducción.

${ }^{16}$ Sobre el "affaire Bet El", como lo denominó La Luz, véase ROSEMBERG, 2010, 70-76.

${ }^{17}$ Véase la Carta de la Asamblea Rabínica al Señor Adolfo Weil (presidente de Bet El), 24 de marzo de 1970, Box 7. Sorprendido de su propia actitud para sobrellevar este tema, Meyer escribió a Weiner "me mantengo prácticamente imperturbable acerca de todo este asunto". MEYER, Marshall. Carta a Eugen Weiner, diciembre de 1971, Box 7, mi traducción.
} 
liturgia y treinta y cinco títulos sobre judaísmo en idioma español, y también había colaborado como uno de los vicepresidentes de la Fundación Magbit en Argentina. Sin embargo, esos primeros intentos de abandonar el país no fueron exitosos. En 1972 volvió a intentarlo, esta vez tentado por una sinagoga de la ciudad de Miami a la que había visitado ese mismo año. En carta al rabino Mendy confesó que estaba pensando en dejar "esta adoptada tierra mía". ${ }^{18}$ Probablemente la sinagoga de Florida no pudo esperar el tiempo que solicitó Meyer para dar una respuesta definitiva, algo que no se animaba a hacer antes que su mujer, Naomi, conociera la comunidad de destino. ${ }^{19}$ Dos años después, al enterarse que el teatro municipal de Haifa estaba en la búsqueda de un gerente general, Meyer envió una solicitud pidiendo que se lo tuviera en cuenta. ${ }^{20} \mathrm{En}$ pocas palabras, aunque Buenos Aires era su segunda tierra y sus hijos eran argentinos, su correspondencia informa varios intentos de continuar su labor fuera de América latina, preferentemente en Israel.

\section{Sociedad y judaísmo}

Para el año nuevo judío de 1968, Marshall Meyer preparó un extenso sermón que introdujo una novedad respecto de los anteriores. Como en otras oportunidades, interpelaba a los miembros de su comunidad acerca de qué significaba ser judío en ese contexto histórico específico. “¿Qué están haciendo ustedes aquí?”, comenzó preguntando aquella noche, "¿cómo pueden creer hoy en día que todavía existe un Dios que les está escuchando? ¿Pensaron qué es rezar? ¿No se dan cuenta que ustedes están jugando aquí? [...] ¿Por qué no admiten que la verdad es que hay pocos de ustedes que realmente creen que hay un real valor en estar aquí? ¿Cuántos de ustedes están porque piensan que es importante acompañar a sus hijos? ¿Cuántos de ustedes porque quieren acompañar a sus padres? ¿Y cuántos sólo y exclusivamente por hábito? ¿Cuántos por mera superstición?". ${ }^{21}$ Este recurso a incómodas preguntas retóricas en sus sermones, habitual en Meyer, a juzgar por la correspondencia resultaba no poco eficaz para movilizar a su audiencia.

\footnotetext{
${ }^{18}$ MEYER, Marshall. Carta al rabino Mendy, Box 6, mi traducción. ${ }^{19}$ MEYER, Naomi. Entrevista realizada por el autor, New York, 26 de mayo de 2015.

${ }^{20}$ MEYER, Marshall. Carta al Teatro Municipal de Haifa de Israel, 14 de noviembre de 1974, Box 6.

${ }^{21}$ MEYER, Marshall. Sermón para Rosh Hashanah [año nuevo judío] 5729, 1968, Box 8.
}

La novedad introducida en este sermón residió en que, dentro de los personajes imaginarios inventados por Meyer para continuar la interpelación a su comunidad, incluyó a "un joven izquierdista sensible". "¿Qué nos diría el joven izquierdista sensible?", preguntó Meyer a su grey. El rabino imaginaba, entonces, que dicho joven se sorprendería al ver "gente relativamente inteligente" todavía en esos tiempos "emborrachándose con la idea de un Dios". "La única cosa real es materia", continuaba el joven izquierdista figurado por el rabino, "por eso, nuestro marxismo es un materialismo filosófico y político". El personaje imaginado representaba a una juventud de clase media urbana crecientemente comprometida con la política nacional, especialmente luego de la intervención a las universidades llevada a cabo por el régimen militar de la Revolución Argentina (1966-1973). ${ }^{22}$

Los cuestionamientos del joven izquierdista ocuparon buena parte del sermón. A diferencia de lo que sucedía con los asistentes a las sinagogas o a las iglesias, decía este joven, la izquierda era consciente de la existencia de villas miserias, de la esclavitud económica y de las carencias de los más necesitados. En lugar de perder el tiempo rezando o ayunando, proseguía, resultaba más útil trabajar para cambiar gobiernos y derribar imperialismos. El joven confesaba haber nacido judío pero estar en contra del "dañino concepto" de un "pueblo judío”. “¿Hay acaso alguien en esta sinagoga que sabe lo que es tener hambre? ¿Qué papel desempeña esta comunidad salvo la de aglutinar un grupo de judíos de clase media para arriba y tratar de cuidar que los hijos no se casen con gentiles? ¿Por qué no se despiertan? ¿Qué están haciendo para mejorar la sociedad? [...] Ustedes no se dan cuenta pero están muertos, o por lo menos todas las ideas que tienen ustedes murieron". ${ }^{23}$

Meyer buscaba interpelar a cada uno de los miembros de su comunidad. Nadie ignoraba que la suya no era una invitación a dejar la sinagoga y unirse a grupos de izquierda. Buscaba, en cambio, que quienes lo escuchaban lograran justificar su presencia con respuestas renovadas, que él intentaba orientar hacia la necesidad de un compromiso social enraizado en la tradición judaica de la Torá. La preocupación en torno a que la juventud pudiese terminar encontrando fuera de

\footnotetext{
${ }^{22}$ Sobre el proceso político que, desde la caída del peronismo en 1955 , fue empujando a algunos jóvenes de clase media a tomar posiciones cada vez más radicalizadas, véanse los clásicos libros de TERÁN, 1991 y SIGAL, 1991.

${ }^{23}$ MEYER, Marshall. Sermón para Rosh Hashanah 5729, 1968, Box 8.
} 
la religión un canal de expresión a aquel compromiso no era privativa del rabino. En 1971, un socio de Bet El dirigió una carta a Meyer y a Edruy Mordejai, también rabino de la cominidad, instándolos a ejercer su liderazgo "espiritual e intelectual" especialmente con los jóvenes, que en ocasiones habían confesado desde el púlpito la ausencia de herramientas para enfrentar las "presiones" que provenían de "toda clase de doctrinas que se oponen a su religión", tanto en la calle como en la universidad. ${ }^{24}$

Bet El es una comunidad ubicada en el barrio de Belgrano $\mathrm{R}$, un área residencial de clase media acomodada de la ciudad de Buenos Aires. Hacia comienzos de los años setenta, la radicalización de los posicionamientos políticos había profundizado una tendencia nacida a mediados de la década del cincuenta, consistente en una fuerte crítica a las actitudes políticas tanto pasadas como contemporáneas de la clase media. La paradoja de esa crítica, sin embargo, era que provenía precisamente de intelectuales y de vanguardias políticas y estéticas, en su mayoría también de clase media (ALTAMIRANO, 2011, 99-127). Estas tensiones, más significativas en las grandes ciudades, también atravesaron la comunidad Bet El.

Uno de sus jóvenes socios, en una carta en la que reconocía tanto su visión ideológica como la pobreza de su vida religiosa, alentaba al rabino a extremar su discurso respecto a la comunidad. Aunque reconocía la labor de Meyer como líder religioso, aspiraba a que "la sinagoga les cuestione [a los miembros de la comunidad] su modo de vida, la pseudo cultura de confort y consumo que enajena a nuestra clase media, de la cual los hermanos de Bet El forman un verdadero catálogo". ${ }^{25}$ Pese a todos los esfuerzos por atenuarla, escribió, "es obvio que Bet El tiene una religiosidad a la burguesa" y que ello "sólo lo van a romper los jóvenes si en Bet El aprenden que este modo de vivir es incompatible con la Torá, y con cualquier intento serio de renovación religiosa y moral". La carta era, como confesaba su autor, "una crítica fuerte" a lo que él juzgaba como una falta de compromiso político de esa comunidad, un llamado a "romper con un sistema de valores individualistas que no tiene nada que ver con la Torá". La crítica del joven judío, esta vez no imaginario sino real, alcanzaba a Meyer. A su juicio,

${ }^{24}$ DINERSTEIN, Luis. Carta a los rabinos Marshall Meyer y Edruy Mordejai, 23 de Septiembre de 1971, Box 1. Véase también, en un sentido similar, la carta de otra socia de Bet El, María Gelassen, dirigida a Meyer, 24 de septiembre de 1971, Box 6.

${ }^{25}$ SCHIFRIN, Leopoldo. Carta a Marshall Meyer, 16 de julio de 1973, Box 1. el rabino tenía "un modo de encarar las cosas que revelaba las limitaciones impuestas por una filosofía individualista a una sensibilidad y a una inteligencia hechas para ir más allá".

No sabemos si Meyer respondió esa carta. Si lo hizo en forma escrita, su archivo no conserva copia de la respuesta. Sí contiene, en cambio, suficiente información como para reconstruir con evidencias el modo probable en que el rabino hubiese contestado esa clase de cuestionamiento. Consciente de los vientos que soplaban en el continente y en Argentina, Meyer encarnaba e intentaba contagiar un judaísmo humanista más social que político. "Queremos que esta comunidad sea la expresión auténticamente religiosa, no política, del judaísmo", declaró a fines de los años sesenta refiriéndose a Bet El. ${ }^{26}$ "Se podría decir válidamente que los que nos hallamos sentados aquí hoy, los que hemos construido esta sinagoga", dijo en uno de sus sermones, "estamos absolutamente locos". Y agregó: "echemos, durante unos instantes, una ojeada objetiva al mundo en que vivimos. Consideremos asimismo el país en el que vivimos. ¿Qué signa nuestra época?: la revolución". ${ }^{27}$ En una época signada por el imperativo de la revolución —en donde "revolución" asumía significaciones diferentes según la constelación ideológica que integrara, pero siempre aludía a un cambio drástico y, en algunos casos, violento- Meyer reivindicaba la "locura" de un compromiso con lo social en el que el ser religioso, el ser judío, se revitalizara a partir del trabajo pacífico de co-creación del mundo.

"Nunca antes en la historia de la humanidad ha sido más importante la sinagoga", dijo en el mismo sermón en el que identificó la revolución como signo de época. Tareas de esa sinagoga eran el esfuerzo "genuin[o] por interpretar la voluntad de Dios", la dedicación "sincer[a] a aumentar la capacidad de amar del hombre, a reforzar su deseo de vivir, a fomentar sus capacidades creadoras [...] de modo que el hombre aún pueda creer y servir". Una sinagoga semejante, pensaba, "no necesita defensa frente al ataque de los ateos o el análisis objetivo de la ruina que es el mundo actual". La última pregunta de este sermón, orientado a actualizar qué significaba ser "un judío creyente" en aquel contexto social específico, resumía el espíritu de su prédica. "En una palabra", finalizaba Meyer, "¿estamos dispuestos a convertirnos en verdaderos

\footnotetext{
26 "Tradición modernizada", Análisis, No. 444, 16 al 22 de septiembre de 1969

${ }^{27}$ MEYER, Marshall. Sermón "Dedication of Bet El”, sin fecha,
} Box 8 , mi traducción. 
judíos, arraigados en el rico suelo de una tradición múltiplemente esplendorosa que trató de enseñar al mundo la inviolable santidad del individuo, estamos dispuestos a correr el riesgo de creer realmente en Dios?" Más que en una filosofía individualista, Meyer insertaba su prédica en una tradición judía que para él consagraba por encima de cualquier otra dimensión el supremo valor del individuo.

\section{El peronismo y la violencia política}

En marzo de 1973, Argentina regresó al régimen democrático con elecciones limpias y, por primera vez en dieciocho años, sin la proscripción del partido peronista. Quedaba atrás un régimen militar que, aunque contó en un comienzo con el apoyo de una buena parte de la prensa, grupos sindicales e importantes sectores de la sociedad civil, pronto dilapidó esas simpatías y enfrentó una ascendente oposición que recorría todo el espectro ideológico. Hacia finales de la década del sesenta, distintas rebeliones en el interior del país habían puesto en evidencia que a la cabeza de esa oposición se encontraban las dirigencias combativas del movimiento obrero y sectores estudiantiles cada vez más cercanos a posicionamientos radicalizados. El regreso definitivo de Perón al país, en junio de 1973, y su contundente victoria en las elecciones de septiembre del mismo año, no bastaron para pacificar un proceso político que, desde finales de la década del sesenta, venía sumando crecientes cuotas de violencia.

El rabino Meyer nunca había simpatizado con el movimiento peronista y menos aún con su líder. Cuando en 1964 Perón intentó un fallido retorno al país (desde 1955 se encontraba en el exilio), debido a que fue forzado a regresar a Madrid en Río de Janeiro, Meyer envió a sus sobrinos en los Estados Unidos una carta explicando el episodio. "Por supuesto, se trata más de un show que de cualquier otra cosa", escribió al comienzo de un largo párrafo en el que afirmaba que el líder justicialista, al que no nombra, "sabe muy bien que no será admitido en el aeropuerto de Ezeiza" y que, en consecuencia, esa "maniobra" no fue más que "un dispositivo de salvación" tendiente a "mostrar a sus seguidores aquí que al menos intentó hacer algo". ${ }^{28}$ Además, preguntaba irónicamente a sus familiares, ¿por qué dejaría millones de dólares y una distendida y pacífica vida en Madrid para volver y sumergirse

${ }^{28}$ MEYER, Marshall. Carta a Carol y Eric Meyer, 8 de diciembre de 1964, Box 6, mi traducción. en lo que de seguro sería una política terriblemente complicada y violenta en Argentina?" En el discurso que ese mismo año pronunció en la inauguración de la sede del seminario alertó sobre el "surgimiento de líderes hipócritas que adulan a las masas". ${ }^{29}$ Más de diez años más tarde, cuando la situación económica durante el gobierno de Isabel Perón se volvió crítica, Meyer atribuirá el desastre socio-económico al resultado "de varios años de irresponsabilidad peronista y de vivir una mentira". ${ }^{30}$ Acudiendo a una metáfora quirúrgica, entonces a la orden del día en la escena política, en esa carta agregó que "felizmente, muchas personas se han dado cuenta del fraude cancerígeno de la ideología peronista, fácil de identificar debido a su falta de algo original o positivo". Meyer era un ciudadano formado en la tradición liberal democrática norteamericana, desde la cual liderazgos como el de Perón se leían a través del tamiz de las experiencias del fascismo europeo. ${ }^{31}$

Aunque no era una festividad popular en Argentina, Meyer solía celebrar el día de acción de gracias por considerar que su mensaje de unidad y solidaridad era la esencia de una humanidad creativa y sensible. Para la celebración de 1974, en medio de una creciente violencia política y con un grupo paramilitar comandado por el ministro López Rega desde el Ejecutivo nacional, la Triple A, asesinando militantes políticos y sociales, Meyer ofició un servicio para norteamericanos residentes en el país, en la Iglesia Norteamericana de Acassuso, provincia de Buenos Aires. "Nosotros, los estadounidenses que compartimos nuestra vida con nuestros hermanos argentinos aquí en este país", comenzó diciendo, "somos testigos de una lucha sangrienta y violenta entre las tendencias ideológicas que enfrenta hermanos contra hermanos y que ha costado innumerables vidas en los últimos años". A diferencia de las citadas anteriormente, las preguntas retóricas esta vez apelaron a la condición humana, no ya a la judía. “¿Por cuánto tiempo continuará la matanza? ¿Cuándo aprenderá el hombre que a través

\footnotetext{
${ }^{29}$ MEYER, Marshall. Discurso en la inauguración de la sede del Seminario Rabínico Latinoamericano, noviembre de 1964, Box 8. ${ }^{30}$ MEYER, Marshall. Carta a Eugene Weiner, 17 de junio de 1975, Box 7, mi traducción.

${ }^{31}$ En 1988, ya en los Estados Unidos, afirmará que en términos prácticos, entre 1930 y 1983 no hubo democracia en Argentina. MEYER, Marshall. Conference on Ethics on the American Jew, Universidad de George Washington, 10 de febrero de 1988, Box 8. La visión que sustraía al peronismo su carácter democrático era compartida por otros norteamericanos en el país. Robert Cox, director del Buenos Aires Herald, en 1985 escribió que el gobierno de Illia (1963-1966) había sido el "primer presidente verdaderamente democrático en más de 30 años" (COX, 1985).
} 
de la muerte y la violencia no se encontrarán soluciones definitivas? ¿Cuándo percibiremos que destrucción no es construcción, que odio no es creatividad, que vendetta no es responsabilidad?", dijo Meyer a su audiencia en una ceremonia que finalizó con la lectura de "A song [Una canción]", de Walt Whitman. ${ }^{32}$

Pocas semanas después de esta celebración, Meyer manifestó su alarma por el aliento del gobierno peronista a los árabes anti-israelíes, por cierta confusión y apatía que percibía dentro mismo del judaísmo argentino y por el accionar de la "alianza de la derecha fascista en Argentina". ${ }^{33}$ La preocupación en torno a la violencia política entre izquierdas y derechas se reiteró en sermones y cartas entre 1974 y 1976. En aquel día de acción de gracias dijo a los norteamericanos allí reunidos que el país necesitaba temperamentos moderados. "Suficientemente padecemos extremismos de derecha y de izquierda, fuego y hielo [...], y políticos que se golpean el pecho", agregó. Más adelante, convocó a su audiencia a trabajar, en la medida que les fuera posible, por "una sociedad humana decente en la que un hombre pueda vivir y amar y morir en paz". ${ }^{34}$

Al año siguiente, su alarma ante la situación nacional había recrudecido. "La violencia extremista continúa sin cesar con al menos 500 asesinatos políticamente inspirados admitidos desde el 1 de julio, cuando el anciano [Perón] murió", escribió en junio de 1975 a su amigo, el rabino Eugene Weiner, "la derecha liquida a la izquierda y la izquierda a la derecha en un círculo vicioso". ${ }^{35}$ Pocos meses después, durante la celebración de Rosh Hashanah [año nuevo judío], rogó una vez más que cese la violencia política. "Oremos para que en Argentina podamos superar nuestros egoísmos", dijo hacia el final de su oración, "pasar de nuestra violencia y crueldad y del extremismo a la democracia responsable para que podamos construir un hogar justo para las generaciones futuras, un hogar en que cada hombre pueda trabajar y jugar, y amar y rezar en paz y armonía". ${ }^{36}$ Cabe notar que Meyer realizó esta plegaria bajo un gobierno elegido en comicios libres y sin prescripciones. Aun así, en varios de sus sermones de este período, como en el citado, la democracia

\footnotetext{
32 MEYER, Marshall. Discurso en la celebración de Thanksgiving Day, 1974, Box 8, mi traducción.

${ }^{33}$ MEYER, Marshall. Carta a Wolfchen Kelman, 26 de noviembre de 1974, Box 6, mi traducción.

${ }^{34}$ MEYER, Marshall. Discurso en la celebración de Thanksgiving Day, 1974, Box 8, mi traducción.

${ }_{35}$ MEYER, Marshall. Carta a Eugene Weiner, 17 de junio de 1975, Box 7, mi traducción.

${ }^{36}$ MEYER, Marshall. Sermón “Time of Judgment”, en Rosh Hashanah, 1975, Box 8, mi traducción.
}

aparecía a sus ojos más como una tarea que como un hecho.

Cuando a esta situación, que ya hacia el final de 1974 juzgaba "snafu" [desastrosa], con mayúscula en todas sus letras, se sume el ajuste económico que en 1975 implementó el gobierno peronista, Meyer pensará en un éxodo no sólo de él sino de una parte de la judería argentina. ${ }^{37}$ Luego de una detallada descripción de la deplorable situación económica, temiendo que el clima social que se avecinaba pudiera tornarse todavía más "desagradable y violento", y espantado ante "el alarmante ascenso del más acérrimo anti-semitismo", sugirió al rabino Weiner, entonces profesor en la Universidad de Haifa, organizar un planificado aliyah colectivo. ${ }^{38}$ "Un grupo de importantes y ricos empresarios argentinos debe ser seleccionado para ir como invitado a Israel", escribió Meyer, "para averiguar con los funcionarios del gobierno apropiados la posibilidad de realizar un proyecto piloto con unas pocas comunidades económicas planificadas". Seguramente al principio se segregarían, pensaba, pero las nuevas generaciones nacerían ya integradas. "Dejemos que los judíos argentinos vivan juntos, que hablen español, en su propio gueto si así lo desean; que ellos manejen sus propios asuntos. Tan pronto como los niños entren a la escuela y al Tsahal [servicio militar israelí], la segunda generación se aclimatará sola". Bien ejecutado, este éxodo de judíos argentinos a Israel "podría resultar más significativo que la menguante aliyah rusa". Si quince años atrás sus primeros intentos de abandonar

\footnotetext{
${ }^{37}$ La expresión "snafu" proviene del ámbito militar norteamericano. Literalmente, significa "Situation Normal: All Fucked Up". Se utiliza, como en este caso hizo Meyer, para designar una situación caótica en la que todos los involucrados están definitivamente perdidos. MEYER, Marshall. Carta a Wolfchen Kelman, 26 de noviembre de 1974, Box 6.

38 "Cuando llegamos aquí en 1959", escribió Meyer, "el tipo de cambio era de 82 pesos por dólar. Hace apenas un mes atrás fue de 1500 pesos por dólar en el mercado oficial y de 3500 en el mercado negro. Ahora el peso oficial es de 3000 pesos por dólar para propósitos financieros, de 4500 para propósitos turísticos (es decir, si quieres comprar dólares para viajar al extranjero) y, en el mercado negro, está flotando alrededor de los 6800 pesos por dólar!!! Esto significa, bueno, puedes imaginar lo que significa. La mayoría de las tarifas de servicios públicos han subido $100 \%$ en los últimos 15 días. El gas ha pasado de 500 a 1500 pesos el litro, un salto del $200 \%$. Los negocios han prácticamente caído hasta la parálisis. Naomi [la mujer de Meyer] ha estado casi histérica durante las últimas dos semanas sin la más mínima idea de cómo manejar la situación. No hay precios para nada y todo el país está paralizado esperando que lleguen los nuevos aumentos salariales que amenazan ser de alrededor del $80 \%$. No hay importación y, por lo tanto, hay muy poca materia prima; y el gran milagro económico argentino parece haberse desvanecido en un desastroso gemido". MEYER, Marshall. Carta a Eugene Weiner, 17 de junio de 1975, Box 7, mi traducción.
} 
Argentina sólo lo involucraban a él y a su familia, el de 1975 revistió un carácter colectivo y urgente. La desesperación de Meyer ante la situación política y económica que experimentaba aquella Argentina explica la reacción que veremos tendrá frente a la noticia del golpe de Estado de marzo de 1976.

\section{La dictadura y los derechos humanos}

Antes de finalizar 1976, Meyer describió el cambio de régimen ocurrido en marzo de ese año en una carta enviada a sus colegas del Movimiento Conservador norteamericano, a los que habitualmente escribía solicitando ayuda financiera para sus instituciones. "La más anticipada revolución argentina tuvo lugar el 24 de marzo de 1976", escribió Meyer. "Fue inusualmente bien planeada e incruenta", continuó, "la Junta Militar tomó el poder y el general Jorge Rafael Videla se convirtió en presidente de la República. Sería difícil sobre exagerar el caos social, político y económico reinante en el país en vísperas de la revolución. Baste decir que si los índices de inflación hubieran continuado como venían, el porcentaje habría alcanzado el $4600 \%$ durante 1976 (actualmente, probablemente llegue al $350 \%$ ). Afirmar que había un vacío de poder es decir lo mínimo. Apenas hubo reacción de los peronistas cuando la ex presidente Isabel Martínez de Perón fue encarcelada en un castillo estilo chateau en la región de los lagos del sur. La corrupción y el desfalco del régimen peronista se está lentamente revelando y las estimaciones más conservadoras estiman la cifra del dinero robado en unos 8 mil millones de dólares". ${ }^{39}$ De este modo, Meyer venía a coincidir con una parte importante de la opinión pública y de la prensa de entonces que juzgaba el quiebre institucional como un golpe de Estado que no sorprendió a nadie, se impuso sin resistencia por parte de sectores civiles ni militares, y ponía fin a un descalabro social, político y económico desgobernado por autoridades ineptas y corruptas. ${ }^{40}$

El panorama de esa nueva Argentina en proceso de "reorganización nacional", tal el modo en que el régimen militar decía concebir su propósito, se completaba en la carta de Meyer con una preocupación que, presente antes del golpe, luego se profundizó. "Sin embargo", escribió Meyer a los rabinos norteamericanos, "a pesar de los logros obtenidos en la lucha contra el terrorismo, Argentina sigue siendo una de las sociedades más

\footnotetext{
${ }^{39}$ MEYER, Marshall. Carta al Movimiento Conservador norteamericano, noviembre de 1976, Box 7, mi traducción.

${ }^{40}$ Sobre este punto, véase NOVARO y PALERMO, 2003, 123-148.
}

violentas del mundo en la actualidad. Se han registrado acerca de 850 asesinatos políticos abiertamente admitidos desde el golpe de Estado y se admite la existencia de más de 300 personas desaparecidas. Los analistas políticos insisten en que las cifras reales son todavía más elevadas. Lo que más preocupa a los demócratas argentinos es la relativa impunidad con que la extrema derecha, las fuerzas paramilitares, continúan operando más allá de la esfera de la ley". ${ }^{41}$ Con los meses, Meyer irá cobrando conciencia de que más que de grupos paramilitares actuando por fuera de la ley, de lo que se trataba era del propio Estado militarizado lanzado a una cacería ilegal de todos aquellos que consideraba enemigos de la nación.

Durante los primeros años del régimen militar Meyer cesó su intento individual de abandonar Argentina; al menos, su archivo no conserva documentos que prueben lo contrario. El sueño de un aliyah colectivo, en cambio, permaneció. En un documental sobre los judíos en Argentina producido por el Servicio Cinematográfico Israelí, realizado en plena dictadura, Meyer aseveró al periodista Eli Cohen que su tarea seguía siendo la de convencer a la judería argentina de que su futuro estaba en Israel..$^{42}$ El énfasis en aliyah no resulta extraño en un propalador del movimiento conservador, que en contraposición al reformista conserva la creencia de la palestina como lugar de los judíos. De modo que ese sueño debe inscribirse en una preocupación más general, el problema de la "asimilación", que Meyer nunca dejó de considerar la principal amenaza que se cernía sobre el futuro del judaísmo, no sólo en Argentina sino en todo el mundo. ${ }^{43}$ Sin embargo, y aunque en ese mismo documental Meyer afirmó que los miembros de la Junta Militar no eran antisemitas, la "difícil" situación general por la que atravesaba el país, sumada a la presencia de "algunos en el gobierno que sí son antisemitas", volvía dicha preocupación "más urgente en Argentina que en Gran Bretaña o los Estados Unidos". 44

En la segunda mitad de la década del setenta, Meyer combinó su compromiso humanitario con las víctimas

\footnotetext{
${ }^{41}$ MEYER, Marshall. Carta al Movimiento Conservador norteamericano, noviembre de 1976, Box 7, mi traducción.

42 “Argentina's Jews. Days of Awe”, 1980, Colección Audiovisual, Archivo Marshall Meyer, Duke University Libraries.

${ }^{43}$ En 1984, luego de transmitir pronósticos alarmantes acerca del descendente número de judíos en Argentina, Meyer afirmará que "cada año hay menos judíos: muchos más judíos mueren que nacen". MEYER, Marshall. "Conferencia sobre la teología de la liberación judía”, Colección Audio, Archivo Marshall Meyer, Duke University Libraries.

${ }^{44}$ Posteriormente, Meyer atribuirá al régimen y a las Fuerzas Armadas en general una "filosofía" antisemita (MEYER, 1983b).
} 
de la dictadura con sus tareas al frente de las instituciones religiosas que había creado. Tanto en el seminario como en Bet El recibió a las madres y familiares de los desaparecidos, colaboró en la presentación de hábeas corpus, visitó detenidos políticos y firmó solicitadas, al tiempo que trabajó junto a los embajadores de Estados Unidos y de Israel, y recorrió instituciones y dependencias militares buscando información, exigiendo posicionamientos públicos en defensa de los derechos humanos o denunciando su violación. ${ }^{45}$ Aunque más tarde lamentará no haber hecho aún más, su compromiso llevó consuelo a muchas víctimas y familiares y colaboró a forzar la libertad de algunas personas. La más célebre fue la de Jacobo Timerman, cuyo best-seller Preso sin nombre, celda sin número el periodista dedicó al rabino. ${ }^{46}$ En 1978, en una entrevista que le realizó el periódico judío Nueva Presencia, confesó que, como rabino, jamás podría perdonarse si repitiera en Argentina el silencio que los rabinos guardaron en Europa en la década del treinta. ${ }^{47}$ Hacia el final de la dictadura, participó de la creación del Movimiento Judío por los Derechos Humanos (MJDH) y tanto en Argentina como en el exterior denunció sin eufemismos la sangría militar. Será este compromiso, tan a contramano de los posicionamientos asumidos por la dirigencia de la Delegación de Asociaciones Israelitas Argentinas (DAIA), la institución más importante de la comunidad judía organizada (SCHENQUER, 2016), el que reconocerá luego Alfonsín convocándolo a integrar la CONADEP. ${ }^{48}$

\footnotetext{
${ }^{45}$ En la colección de documentos de Marshall Meyer de la Universidad de Duke pueden consultarse algunas conmovedoras cartas al respecto. Por ejemplo, las intercambiadas entre el rabino y Débora Benchoam-una adolescente de 16 años que permaneció presa cuatro años sin ningún cargo formal y que finalmente fue liberada en 1981 gracias a las gestiones del congresista norteamericano William Lehman, cuyo apoyo consiguió Meyer- o las cartas de agradecimiento por el acompañamiento y la ayuda ofrecidas a las víctimas y a sus familias, como la que Mario Zareceansky escribió a Meyer el día 23 de septiembre de 1987, Box 2.

${ }^{46}$ Sobre la liberación de Timerman, véase REIN y DAVIDI, 2011. ${ }^{47}$ MEYER, Marshall. "Para mi es muy doloroso que en la Argentina de hoy las palabras 'Derechos Humanos' hayan devenido desagradables y no puedan decirse", entrevista realizada por Heman Schiller, Nueva Presencia, 22 de diciembre de 1978. Véase también la exhibición "I Have No Right to Be Silent", The Human Rights Legacy of the Rabbi Marshall T. Meyer, http://library.duke. edu/rubenstein/human-rights/exhibits

${ }^{48}$ Según Schenquer, la actitud de la DAIA frente al régimen militar habría transitado primero por una fase de acomodamiento (197677), luego por una de aceptación (1977-1980), y finalmente por una de distanciamiento (1980-1983). Sobre la relación de Meyer con la DAIA, véase FAINSTEIN, 2013, 140-2, y ROSEMBERG, 2010, 85-88. Estos diferentes posicionamientos de la comunidad judía frente al régimen militar llegaron a la prensa internacional de la época. Al respecto, puede verse el interesante artículo de FREED, 1980.
}

Al mismo tiempo, la correspondencia de esta época evidencia la satisfacción de Meyer en cuanto al crecimiento espiritual y material de sus instituciones. En 1979 estaba construyendo dos nuevos edificios, el seminario había superado los trescientos estudiantes y la escuela primaria de Bet El rondaba los cuatrocientos inscriptos. ${ }^{49}$ Para 1981, su comunidad superaba las mil familias (un crecimiento considerable si se tiene en cuenta que comenzó con una decena en 1963), se había logrado la afiliación de más de veinte comunidades en todo el país y el seminario contaba con una nueva sede. ${ }^{50}$ Aunque efímera, la prosperidad que gracias a la liberalización de la economía una parte de la clase media urbana experimentó durante los primeros años de la dictadura, alcanzó a las instituciones fundadas por Meyer. El rabino, por otra parte, distinguía la cuestión de los derechos humanos de la política económica. En 1981 recibió en su sinagoga la visita de José Alfredo Martínez de Hoz, el emblemático ministro de economía del régimen militar, poco tiempo después de haber dejado su cargo.$^{51}$ Cuando más adelante recuerde esta época, la memoria de la lucha por los derechos humanos y las dificultades que debió enfrentar para llevarla a cabo tenderán a marginar estos otros aspectos.

Ese año, cuando las desapariciones ya habían disminuido notablemente, Meyer volvió a tantear posibilidades laborales afuera del país, como la presidencia de la Universidad de Haifa en Israel o algún empleo en los Estados Unidos. ${ }^{52}$ El 3 de abril de 1983, aceptó formalmente el cargo de vicepresidente

\footnotetext{
${ }^{49}$ MEYER, Marshall. Carta a la Comunidad Bet El, marzo de 1979, Box 6; y MEYER, Marshall. Carta al Movimiento Conservador norteamericano, octubre de 1979, Box 7.

${ }^{50}$ MEYER, Marshall y RINGLER, Mario. Conferencia de prensa, 10 de diciembre de 1981, Box 8. Aun cuando Meyer era famoso por la exageración de sus estadísticas (costumbre a la que se aludía entre sus amigos como "números Marshall"), el crecimiento de la comunidad y del seminario fue sin duda significativo. Entrevista a Naomi Meyer realizada por el autor, New York, 26 de mayo de 2015.

${ }^{51}$ Esta distinción entre la política económica y la represiva era compartida por otros norteamericanos como su amigo y director del Buenos Aires Herald, Bob Cox. Cox tenía amistad personal con un miembro del equipo económico militar y, al mismo tiempo, arriesgó su vida denunciando en su periódico noticias acerca de la represión ilegal. COX, Bob. Entrevista realizada por el autor, Charleston, Carolina del Sur, 21 y 22 de mayo de 2016.

52 "Pero si Haifa fallara", escribió a sus amigos Anita y Eugene Weiner en Israel, "definitivamente comenzaré a buscar un trabajo en los Estados Unidos, además de escribir a Dulzin, de la Agencia Judía, preguntando si hay algo que él pueda ofrecerme. ¿Se les ocurre algo a ustedes? [...] Si oyen hablar de algo en Nueva York o durante tus viajes este verano, no tengo ni que pedirte que me tengas presente". MEYER, Marshall. Carta a Eugene Weiner, 22 de julio de 1981, Box 7, mi traducción. En octubre, la candidatura de Meyer a la presidencia de la Universidad de Haifa "estaba en la mesa, en competencia con otras candidaturas". BARTEL, A. Carta
} a Marshall Meyer, 4 de octubre de 1981, Box 7. 
de la Universidad de Judaísmo de Los Ángeles, en California. En la misma carta pedía comenzar su trabajo un año después, dado que necesitaba tiempo para resolver pendientes en Argentina. ${ }^{53}$ Poco después de asumir sus funciones en la Universidad de Judaísmo, decidió abandonarla porque "no tenía nada de judaísmo y menos de universidad". ${ }^{54}$ Su próxima estación fue la definitiva. En septiembre de 1985 llegó a la comunidad B'nai Jeshurum, la sinagoga askenazí más antigua de New York, en la que permaneció hasta su muerte en diciembre de 1993.

La comunidad neoyorkina estaba prácticamente en ruinas y había que rehacerla casi desde cero. Meyer se sentía otra vez como en Buenos Aires en el año 1959, "sólo que con 25 años más encima", como escribió a muchos amigos. ${ }^{55}$ En cualquier caso, New York era "mucho más mi casa que Los Ángeles" ${ }^{56}$ y vivir a dos cuadras de su hija Anita representaba un estímulo invalorable.$^{57}$ Aunque durante los primeros meses de su estadía en Los Ángeles escribió al presidente de Bet El que todavía no había cerrado las puertas a un eventual regreso a Argentina, una vez en New York tomó la decisión de permanecer allí, volviendo periódicamente a visitar a su familia (dos de sus hijos vivían en Buenos Aires) y a sus amigos..$^{58}$ "Es verdad que después de estar en Argentina durante tanto tiempo este es un lugar muy tranquilo y pacífico", escribió Meyer al rabino Albert Lewis poco después de arribar a Nueva York, "estoy muy feliz de estar de vuelta en casa en los Estados Unidos y ansioso de participar activamente en la vida de este país". ${ }^{59}$ New York "es una ciudad exitantísima", escribió a su amigo Wegman, con una vida cultural "impresionante y creo que inigualable". ${ }^{60}$ New York

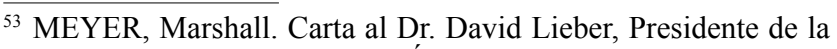
Universidad de Judaísmo de Los Ángeles, 3 de abril de 1983, Box 1.

${ }^{54}$ Véase, por ejemplo, MEYER, Marshall. Carta al rabino Guillermo Bronstein, 2 de diciembre de 1985, Box 1; MEYER, Marshall. Carta a Etel y Dany, 2 de diciembre de 1985, Box 1.

${ }^{55}$ Ibid, y varias otras cartas, por ejemplo: MEYER, Marshall. Carta a Marcos Weinstein, 4 de diciembre de 1985, Box 4; y MEYER, Marshall. Carta a María Gelassen, 4 de diciembre de 1985, Box 6.

${ }^{56}$ En New York "la gente es distinta y no de plástico y superficial como son la mayoría en el Oeste". MEYER, Marshall. Carta al rabino Guillermo Bronstein, 2 de diciembre de 1985, Box 1. Su breve paso por Los Ángeles fue "una de las peores experiencias de mi vida [...], una pesadilla en todo sentido". MEYER, Marshall. Carta a Etel y Dany, 2 de diciembre de 1985, Box 1.

${ }^{57}$ MEYER, Marshall. Carta a Samuel Wegman, 4 de diciembre de 1985, Box 6.

${ }^{58}$ MEYER, Marshall. Carta a Samuel Wegman, 11 de marzo de 1985, Box 6.

${ }^{59}$ MEYER, Marshall. Carta al rabino Albert Lewis, 18 de octubre de 1985, Box 1, mi traducción.

${ }^{60}$ MEYER, Marshall. Carta a Samuel Wegman, 4 de diciembre de 1985, Box 6.
}

constituyó para Meyer un verdadero regreso a casa, un aliyah cultural. Desde allí mantuvo tanto como pudo el contacto con sus amigos y familiares en Argentina. La distancia no impidió que Meyer siguiera siendo el principal interlocutor y consejero de los miembros de la comunidad y del seminario.

\section{La transición a la democracia: de la denuncia a la responsabilidad}

El 15 de julio de 1983, todavía en Buenos Aires, Meyer comenzó su sermón del viernes en Bet El diciendo: "Me siento sucio, tengo vergüenza, veo oscuridad, soy impuro, hemos blasfemado". ${ }^{61} \mathrm{La}$ interpelación esta vez estaba dirigida a considerar la responsabilidad que cabía a cada uno como ciudadano frente a los crímenes de la dictadura que se comenzaba a dejar atrás. El día anterior, la Junta Militar había dado a conocer por televisión el "Documento final sobre la lucha contra la subversión y el terrorismo", en donde negaba la existencia de información sobre los desaparecidos, cargaba todo lo actuado por el régimen en materia de represión a la cuenta de la "guerra sucia" y encomendaba a Dios las almas de los "subversivos". "Tendría que volver cuarenta o cincuenta años atrás", confesó el rabino, "para poder encontrar documentos tan viles, tan obscenos, tan pornográficos en el último sentido de la palabra, tan carente de valor y respeto mínimo para la vida del hombre [...] Este documento, hermanos judíos, es un Jilul Hashem: una desecración (sic) y profanación del nombre de Dios". ${ }^{62}$

Meyer consideraba que la utilización del nombre de Dios por parte de la dictadura militar era una profanación. Traduciendo el comunicado militar al registro bíblico, expresó: "Dios dijo a Caín: ‘dónde está Abel, tu hermano?', y Caín contesta: 'yo no sé, no sé dónde están los desaparecidos". Frente a "un documento sin justicia, sin ley, sin Torá [...] me siento sucio, avergonzado. ¿Cómo te sentís vos? ¿Sentís algo?" ${ }^{63}$ Sus palabras esa tarde estuvieron casi íntegramente dedicadas a los años del régimen militar que concluía dejando un saldo de muertes y desapariciones inédito en el país, además de una guerra perdida con Gran Bretaña por el territorio de las Islas Malvinas. Los únicos pasajes en que este sermón trascendió ese marco temporal fueron los

\footnotetext{
${ }^{61}$ MEYER, Marshall. Sermón en Bet El, 15 de julio de 1983, Box 8.

${ }^{62}$ Véase también MEYER, 1983a, 2 y 21.

${ }^{63}$ MEYER, Marshall. Sermón en Bet El, 15 de julio de 1983, Box 8.
} 
dedicados a recordar otros sermones, hostiles a la violencia política de izquierda y al terror paramilitar, pronunciados diez años atrás. "Desde este mismo púlpito en el que en 1973, 1974, 1975, fue condenada Isabelita, López Rega, ERP [Ejército Revolucionario del Pueblo] y los Montoneros [estas dos últimas habían sido las organizaciones insurreccionales armadas más importantes de aquel período], con las mismas palabras y el mismo tono que empleo ahora, fueron asesinos todos los terroristas, y el gobierno de las Fuerzas Armadas empleó los mismos asesinatos, los mismos métodos, burlando la ley, burlando cualquier cosa que pudiera crear un futuro para este país". En 1984 declaró a la revista Humor que, si bien no equiparaba el terrorismo de Estado con la "delincuencia asesina", era "irresponsable desde el punto de vista histórico" olvidar que "la extrema izquierda [fue] una importante parte del cuadro". ${ }^{64}$ Esa visión de condena a "las dos violencias" de los años setenta, a la que más tarde se calificará peyorativamente como "teoría de los dos demonios" aun cuando no igualara a unos y otros, todavía al comienzo de los años ochenta constituía la de una parte del progresismo. ${ }^{65}$ Así lo corroboran los documentos que desde mediados de la década del setenta emitieron las dos primeras organizaciones de derechos humanos en Argentina, la Asamblea Permanente de Derechos Humanos y el Movimiento Ecuménico por los Derechos Humamos, mucho antes de que cobrara voz oficial con el advenimiento del gobierno de Alfonsín (CARASSAI, 2009 y 2016).

Poco antes de abandonar Argentina, en un acto en la Plaza de la República organizado por el MJDH, Meyer pronunció un discurso que tituló "Escoged, pues, la vida". ${ }^{66}$ "Estamos reunidos aquí esta noche

\footnotetext{
${ }^{64}$ MEYER, Marshall. "Marshall Meyer", reportaje realizado por Mona Moncalvillo, Humor, 12 de abril de 1984.

65 "Estos últimos diez años de sangre, dolor y desencuentros", editorializó el periódico Nueva Presencia en 1980, "generaron en nuestro país una nueva antinomia: las dos Argentinas que han sufrido la esquizofrenia de la violencia. Por un lado, la Argentina de Aramburu, Sánchez y decenas de militares o policías, de todos los rangos, que llora a quienes cayeron bajo la artera metralla del terrorismo nihilista. Por el otro, la Argentina doliente de esa verdadera multitud de sombras que son los familiares de los desaparecidos, que han aprendido a sobrellevar su sufrimiento con dignidad, mientras esperan el milagro de volver a reencontrarse algún día con sus seres queridos tragados por la noche". PÉREZ ESQUIVEL, 1980, 1. Este mismo año, comprometiendo al diario a ocultar su autoría, Meyer publicó un largo artículo en el Buenos Aires Herald en el que presentaba, numerados, una serie de puntos a su juicio innegables respecto del "terrorismo" civil posterior a 1973 y de la "guerra sucia" librada por el Estado luego del golpe. Véase "A Glaring Need to Face the Truth", Buenos Aires Herald, 3 de junio de 1980.

${ }^{66}$ MEYER, Marshall. Discurso "Escoged, pues, la vida" en el acto del MJDH, 25 de abril de 1984, Box 8.
}

porque tenemos memoria", dijo. El motivo principal del acto era conmemorar el $41^{\mathrm{O}}$ aniversario de la batalla del Gueto de Varsovia. Sin embargo, no sólo dedicó varios párrafos a la reciente historia argentina sino que también leyó desde ella la tragedia que se conmemoraba. "Nadie ayudó a los judíos en los campos y en los guetos", señaló, "el mundo se mantuvo al margen cuando los gritos que salían de las cámaras de gas eran ahogados por las excusas de naciones y líderes: no era conveniente interferir. Por otra parte, no todos los judíos eran inocentes. No resultaba inteligente debilitar el esfuerzo de guerra utilizando aviones y armas para ayudar a unos pobres judíos que de todos modos estaban destinados a morir" ${ }^{67}$ Meyer pensaba que casi nadie en Argentina había ayudado a las víctimas de la dictadura, que una parte del mundo (el Estado de Israel incluido) también había preferido permanecer al margen, y que los dirigentes de la DAIA habían repetido aquellos argumentos de los años treinta, en cuanto a que era mejor no levantar la voz para no avivar el antisemitismo. ${ }^{68}$

En un coloquio sobre violaciones a los derechos humanos, más tarde dirá que en Argentina aprendió la "terrible lección" del Holocausto, en el sentido de que hasta entonces no había entendido cómo se podía vivir en "Treblinka o Bergen-Belsen o Dachau o Auschwitz y pretender que no se sabía nada" (MEYER, 1995, 359364). Esta lección la aprendió sin negar la especificidad del holocausto. En varias oportunidades se manifestó en contra de que lo sucedido en Argentina sea homologable al genocidio judío (MEYER, 1983c) ${ }^{69}$ En parte por

\footnotetext{
${ }^{67}$ Véase también "Meyer, dura crítica a los militares", Clarín, 28 de abril de 1984

68 “Aquí en la Argentina", dijo Meyer hacia el final de su discurso, "hemos vivido nuestra propia larga noche de horror y crimen en la cual nuestros compatriotas se mantuvieron al margen, callados, en un silencio dictado por el miedo, o la comodidad, o la incredulidad, o la falta de solidaridad humana, o la falta de compasión y sensibilidad, mientras los gritos de los torturados, de aquellos tirados vivos al Río de la Plata desde helicópteros, de aquellos quemados en los crematorios argentinos, de aquellos sepultados en fosas comunes en los campos de concentración argentinos, todos esos llantos y gritos eran ahogados por voces conocidas que decían: 'debe haber un motivo', 'por algo será', 'debemos defender a la patria del terrorismo que destruirá nuestros valores occidentales y cristianos' [...] Y el horror mayor es que todavía estamos escuchando las mismas voces repitiendo los mismos sórdidos argumentos". MEYER, Marshall. Discurso "Escoged, pues, la vida" en el acto del MJDH, 25 de abril de 1984, Box 8. Como declaró este mismo año a la revista Humor, Meyer se contaba entre quienes pensaban que "la sociedad argentina fue cómplice" de lo ocurrido durante la dictadura. "Marshall Meyer", reportaje realizado por Mona Moncalvillo, Humor, 12 de abril de 1984. ${ }^{69}$ MEYER, Marshall. Entrevista de Leonardo Senkman para el proyecto "La represión en la Argentina bajo los gobiernos militares y los judíos (1976-1983)”, 23 de julio de 1991, Box 8.
} 
la especificidad de la empresa de exterminio nazi, en parte porque estaba convencido de que durante la dictadura argentina los judíos no habían sido arrestados por ser judíos, aunque una vez capturados, el hecho de ser judío incrementara los tormentos. ${ }^{70}$

La correspondencia que Meyer mantuvo con sus amigos de Bet El a partir de 1985 constituye una vía atípica para explorar la memoria que en los años ochenta comenzó a construirse de los años de plomo, al menos dentro de una comunidad específica de la clase media argentina, probablemente informada más que el promedio de la población de las violaciones a los derechos humanos por la activa participación de su líder en su denuncia. Los temas de esta correspondencia son variados: los avatares económicos, las instituciones judías, los conflictos internos en Bet El y el seminario, la ausencia irremplazable de Meyer y las correspondidas manifestaciones de cariño entre el rabino y su comunidad. Muchas de ellas proveen, además, información valiosa sobre cómo algunos miembros de Bet El y el propio Meyer experimentaron los años iniciales de la post-dictadura y comenzaron a elaborar una primera memoria de la represión.

Antes de finalizar 1985, Marcos Weinstein, integrante del MJDH, escribió a Meyer una larga carta en la que mostraba decepción por la idiosincrasia del país y la de su propio entorno. Psiquiatra, profesor universitario y padre de Mauricio Weinstein, desaparecido en 1978, describió con frustración la situación interna dentro de los movimientos de derechos humanos. Luego de comentar las diferencias que habían surgido dentro de las Madres de Plaza de Mayo (que terminarían dividiéndolas en dos grupos), y de mencionar que en el MJDH "no estamos mejor", Weinstein escribió un párrafo sobre el lugar de los derechos humanos en la sociedad argentina y, particularmente, en la comunidad judía. "11 "El tema de los derechos humanos ya no moviliza", explicó Weinstein al rabino, "y sólo

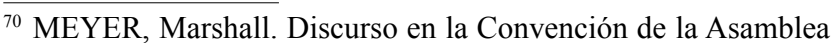
Rabínica, 12 de marzo de 1985, Box 8. Sobre la visión de Meyer respecto del antisemitismo en distintos momentos de la Argentina, véanse MEYER, 1972, y las entrevistas aparecidas el 28 de septiembre y el 5 de octubre de 1983 en las revistas Siete días y El porteño respectivamente, reproducidas también en Maj'shavot/ Pensamientos, Año XXII, No. 4, 1983, 5-19.

${ }^{71}$ Tanto en el conflicto desatado dentro de las Madres de Plaza de Mayo como en el que tuvo lugar al interior del MJDH, las diferencias obedecieron al grado de independencia política de los organismos o sus dirigentes. En ambos movimientos hubo quienes prefirieron asumir una voz partidaria, opositora al gobierno de Alfonsín, y quienes opinaban que los organismos no debían identificarse con ningún partido, ni a favor ni en contra.
}

se puede seguir en base a una postura ideológica democrática y pacífica que sustentamos pero que no es fácil de solventar, con poca gente, poco dinero, y bajo nivel de integración de las generaciones nuevas en el compromiso ideológico". ${ }^{72}$ En cuanto a las instituciones del judaísmo oficial, Weinstein comentó que seguían "los choques con la comunidad organizada" y que los del MJDH seguían siendo "los 'schcutzim' [la basura] de la judería argentina". ${ }^{73}$ En el mismo sentido, uno de sus fundadores escribió poco después que el movimiento constituía una experiencia "algo marginal con respecto a la judeidad institucional". ${ }^{74}$

Otros dos miembros de Bet El escribieron a Meyer más o menos para la misma época que el año 1985 había sido, políticamente hablando, "conflictivo y confuso". "Entiendo que a través de la gente que te escribe debés estar enterado de lo que aquí ocurre", contaban a su rabino, "de lo difícil y dura que se está volviendo sostener la bandera de los Derechos Humanos". ${ }^{75}$ Juzgaban a los argentinos "saturados del tema, como si lo económico estuviera por encima de toda otra cuestión", y comentaban que un pedido que habían realizado por la libertad de catorce presos políticos "no interesa a nadie salvo a los afectados".

Así y todo, el MJDH, que había comenzado un grupo minúsculo de personas cuatro años atrás, para 1986 también tenía buenas noticias. El director del periódico judío Nueva Presencia y co-fundador del movimiento, Herman Schiller, en marzo de ese año comunicó a Meyer que habían logrado vencer la resistencia a reconocerlos de otros organismos de derechos humanos. Aunque también mencionó las discusiones originadas en torno a la no partidización del movimiento, comentó con alegría que habían incorporado a Hernán Invernizzi, un joven que había pertenecido a la guerrilla y todavía continuaba en prisión. ${ }^{76}$ Lo particular de esta incorporación era que Invernizzi no era judío. En el penal de Villa Devoto,

\footnotetext{
${ }^{72}$ WEINSTEIN, Clara y Marcos. Carta a Marshall Meyer, 26 de diciembre de 1985, Box 4.

${ }^{73}$ Ibid.

${ }^{74}$ SCHILLER, Herman. Carta a Marshall Meyer, 2 de marzo de 1986, Box 2.

${ }^{75}$ GRINSZTAJN, Ana y Manolo. Carta a Marshall Meyer, 1 de febrero de 1986, Box 2.

${ }^{76}$ Un integrante del MJDH, Pedro Ressels, aceptó una candidatura ofrecida por el Partido Comunista, ocasionando discusiones con el resto del movimiento que terminaron con su alejamiento. El episodio fue aprovechado por la derecha judía para identificar al movimiento con la izquierda, y el MJDH debió publicar una solicitada en los diarios aclarando que, como movimiento, no se identificaba con ningún partido en especial y respetaba a todos los de vocación democrática.
} 
Schiller y los miembros del movimiento le entregaron una carta en la que afirmaban que, para ellos, "judaísmo no es una cuestión sanguínea si no el reconocimiento al viejo humanismo contestatario de los profetas", una concepción en sintonía con la prédica de su rabino. ${ }^{77}$

Ese año Meyer visitó Argentina. Además de entrevistarse con organismos de derechos humanos, ofreció un ciclo de tres conferencias en Bet El cuyo tema fue "El proyecto de la Sinagoga en las próximas décadas". En ellas encontró más de una oportunidad para hablar tanto de la realidad Argentina contemporánea como de sus memorias del pasado reciente. Condenó los fascismos "de derecha o de izquierda", el fanatismo "del comunista ortodoxo que predica que los fines justifican los medios" y el del "nazi que dice la misma cosa"; y recordó que "el judaísmo sobrevivió porque nunca se dedicó sólo al judaísmo sino a la humanidad". ${ }^{78}$ A propósito de la heterogeneidad del pueblo judío, en esa misma conferencia volvió a criticar la actitud de la oficialidad judía durante la dictadura. "Cada vez que se nos quiso dominar, hubo un intento de homogeneización", dijo, y como "ejemplo perfecto" de ello agregó: "¿recuerdan que desde 1976 a 1983 había un Proceso en el país? ¿Y cuál fue la posición de la comunidad judía? Unificación. Una sola voz, como si no hubiéramos aprendido nada de la Alemania nazi".

En este mismo ciclo, a los adultos de la comunidad los impelió a "jamás permitir una vuelta al pasado [...], sería trágico volver al 'quedate piola, en el molde' y al 'no te metás'. Ese es el enemigo de la democracia". ${ }^{79}$ También recordó la resistencia que durante la dictadura debió enfrentar por recibir a las madres de los desaparecidos en la comunidad que ahora lo escuchaba. ${ }^{80}$ Poco después, en una conferencia en los Estados Unidos, Meyer se refirió a ello como "la decisión ética más delicada" que había debido enfrentar a lo largo de toda su vida. En 1977,

\footnotetext{
${ }^{77}$ SCHILLER, Herman. Carta a Marshall Meyer, 2 de marzo de 1986, Box 2. Meyer manifestó en varias oportunidades que el judaísmo era, fundamentalmente, "una actitud ante la vida" más que una cuestión de sangre. En 1962, la madre de un muchacho judío le pidió que evitara el casamiento de su hijo con una joven cuya conversión al judaísmo ella consideraba fraudulenta. El rabino le contestó que su hijo conocía bien a su futura mujer, que además iba a la sinagoga y estaba estudiando hebreo y que era ella como madre judía quien estaba siendo víctima de un prejuicio que "no es más agradable si proviene de un judío que de un anti-semita". Correspondencia entre POPELL, Berta y MEYER, Marshall, 21 y 28 de septiembre, y 3 de octubre de 1962, Box 7.

${ }^{78}$ MEYER, Marshall. Primera conferencia en su visita a la argentina de 1986, Box 9.

${ }_{79}$ MEYER, Marshall. Tercera conferencia en su visita a la argentina de 1986, Box 9.

${ }^{80}$ MEYER, Marshall. Sermón, 26 de mayo de 1986, Box 8.
}

memoró, un miembro del Comité Ejecutivo de Bet El le solicitó que evitara la presencia de las madres de los desaparecidos en los servicios religiosos de la sinagoga. "Yo, por ejemplo", recordó Meyer que dijo uno de los directores, "siento que tú, Marshall, como rabino, no tienes derecho a poner en peligro a tu comunidad por tus opciones políticas". ${ }^{81}$ Aunque el Comité Ejecutivo no aceptó la renuncia que Meyer presentó, parece claro que su solidaridad con los familiares de los desaparecidos debió enfrentar resistencias no sólo en la judería oficial sino también en su propia comunidad. Cuando años más tarde Rafael Zuchowicki, amigo de Meyer y directivo de Bet El, recuerde en un programa de radio esas discusiones internas, a la pregunta de si la comunidad acompañaba a su rabino en la lucha por los derechos humanos, responderá "yo diría que estaba solo". 82

A finales de 1986 el parlamento argentino sancionó la ley de Punto Final y al año siguiente la ley de Obediencia Debida, favoreciendo a los imputados por los delitos cometidos desde el Estado durante la dictadura militar. ${ }^{83}$ Meyer, que tenía gran aprecio por Alfonsín (lo consideraba "un milagro mayúsculo" en la historia argentina), ${ }^{84}$ apoyó a las organizaciones que se movilizaron en contra de las leyes, firmó solicitadas y responsabilizó a la sociedad por no oponerse masivamente. "Si hay obediencia debida", dijo en una entrevista periodística en 1987, "es porque no había tanta gente interesada en el castigo de los torturadores". ${ }^{85}$ A comienzos de ese año, una artista plástica escribió al rabino comentándole que desde que se enteró cuál era su posición sobre la ley de Punto Final había vuelto a sentir que en Bet El había lugar para ella. La joven artista, además, le comentó una frustración personal al respecto. "Lancé una convocatoria a los plásticos que conozco para hacer una 'ambientacióndecoración' en toda la zona aledaña al Congreso durante los días que se llevara a cabo la discusión de la

\footnotetext{
${ }^{81}$ MEYER, Marshall. Conference on Ethics on the American Jew, George Washington University, Feb. 10, 1988, Box 8, mi traducción. ${ }^{82}$ Programa de radio "Percepciones. Una mirada desde lo judío", conducido por Héctor Timerman y los rabinos Daniel Goldman y Mario Rojzman, FM Jai, sin fecha, Colección Audio, Archivo Marshall Meyer, Duke University Libraries.

${ }^{83}$ La ley de Punto Final (23.492), promulgada el 24 de diciembre de 1986, sancionaba la extinción de la acción penal para toda persona acusada de cometer delitos derivados de acciones violentas que no hubiese sido citada a prestar declaración antes del 23 de febrero de 1987. La ley de Obediencia Debida (23.521), dictada el 4 de junio de 1987, eximió de culpa a los miembros de las Fuerzas Armadas con grado inferior a coronel por considerar que cumplían órdenes. 84 "60 minutos de Australia", sin fecha, Colección Audiovisual, Archivo Marshall Meyer, Duke University Libraries.

85 "La obediencia debida se debe a la amnesia colectiva", Página 12, 1 de septiembre de 1987.
} 
'ley”, escribió, "pero no conseguí que la gente diese su apoyo como esperé" ${ }^{86}$ Las movilizaciones en contra de las leyes no evitaron su sanción. Ello trajo desazón a muchos activistas de los derechos humanos y enemistó al gobierno de Alfonsín con las organizaciones que todavía no lo estaban. En 1987, año electoral, Marcos Weinstein escribió a Meyer que la cuestión de las leyes no había sido tema central en el debate de los candidatos, "salvo para la izquierda 'loca" ". 87

Ante el temor a que lo sucedido durante aquellos años se fuera extinguiendo de la memoria social, ese mismo año un grupo pequeño de afectados por el terrorismo de Estado, entre los que se contaba Weinstein, comenzó a proyectar la creación de la "Casa del Desaparecido". Su idea fue crear "un pequeño Yad Vashem [memorial de las víctimas del holocausto]", no un museo sino algo "activo, dinámico, docente, móvil y educador", que conjugara objetos y recuerdos y estimulara de ese modo una memoria dinámica. ${ }^{88}$ El proyecto debió enfrentar, a juicio de Weinstein, un tiempo hostil. En 1988 comentó al rabino que "las organizaciones de Derechos Humanos siguen desgranando sus integrantes", al tiempo que pasó revista a las defecciones en las organizaciones que continuaban activas. "Ha decaído la militancia con motivo de la difícil situación del país en lo político y en lo económico", escribió Weinstein terminando de bosquejar un sombrío panorama. ${ }^{89}$ Pocos meses antes de morir Meyer, en agosto de 1993, Weinstein y su esposa volverán a escribirle. Aún con algunos proyectos en su "Fundación Memoria", la decepción que transmiten es inequívoca. "Los movimientos y organismos de Derechos Humanos se están agotando. La reivindicación de los desaparecidos se va esfumando como el recuerdo de sus caras, de sus cuerpos, de sus frases, de sus fechas", cuentan a su rabino en las últimas noticias que al respecto conserva su archivo personal. ${ }^{90}$

\section{Epílogo y conclusiones}

Meyer murió antes de que comenzara a vislumbrarse una nueva época para los movimientos de derechos humanos en Argentina. Los indultos que

\footnotetext{
${ }^{86}$ ESSES, Lili. Carta a Marshall Meyer, 20 de enero de 1987, Box 2. ${ }^{87}$ WEINSTEIN, Marcos. Carta a Marshall Meyer, 14 de octubre de 1987, Box 4.

${ }^{88}$ WEINSTEIN, Marcos. Carta a Marshall Meyer, 27 de agosto de 1987, Box 4.

${ }^{89}$ WEINSTEIN, Marcos. Carta a Marshall Meyer, 27 de abril de 1988, Box 4

${ }^{90}$ WEINSTEIN, Marcos. Carta a Marshall Meyer, 16 de agosto de 1993, Box 4.
}

el presidente Carlos Menem sancionó en los albores de su gobierno (1989-1999) desalentaron las esperanzas del rabino respecto del futuro de la democracia en el país. De hecho, Meyer nunca atribuyó gran vocación democrática a los argentinos. Cuando el periodista Barry Lando lo entrevistó para su programa de televisión " 60 Minutos", frente a la pregunta acerca de los cargos bajo los cuales los desaparecidos eran detenidos, Meyer exclamó: “¡Ningún cargo! ¡No sea ingenuo! ¿De qué 'cargos' está hablando? No había ley, no había Justicia; no piense como un estadounidense, jestá en Argentina aquí! ¿A qué se refiere con "cargos" "? ${ }^{91}$ Terminada la dictadura, sus sermones y conferencias en la comunidad Bet El incluyeron elementos básicos de una instrucción cívica. "Argentina tiene que aprender qué es democracia", dijo en 1984, "tiene que comprender que democracia es forma de vivir y trabajar juntos, pero trabajar subrayado, forma de tener respeto por distintas opiniones, sin agredir uno a otro, con oposición". ${ }^{92}$ Dos años después manifestó que, más allá de que hubiera elecciones, no existía vocación democrática en el país. ${ }^{93}$

De ahí que en sus intervenciones públicas y su correspondencia de la década del ochenta se reiteren referencias a lo que él juzgaba como una propensión típicamente argentina, la de creer en ídolos y mitos y, una vez desvanecidos, volver a construir nuevos. "A los argentinos nos gustan los mitos", dijo en un plural que solo aparentemente lo incluía, "a mí me gusta romperlos". ${ }^{94} Y$ en el mismo sentido agregó: "no hagan con Alfonsín lo que hicieron con Perón. Argentina tiene una enorme capacidad para crear mitos". ${ }^{95}$ Su visión sobre la sociedad argentina nunca dejó de combinar entusiasmo por la vida cultural y afectiva de los argentinos con estupor ante un elemento disgregador y anómalo que juzgaba democráticamente distribuido, adentro y afuera de la colectividad. ${ }^{96}$ En este sentido, su

\footnotetext{
91 “A Dirty War", programa de televisión "60 minutos", Colección Audiovisual, Archivo Marshall Meyer, Duke University Libraries, mi traducción.

${ }^{92}$ MEYER, Marshall. "Conferencia sobre la teología de la liberación judía", Colección Audio, Archivo Marshall Meyer, Duke University Libraries.

${ }^{93}$ MEYER, Marshall. Tercera conferencia en su visita a la argentina de 1986, Box 9.

${ }^{94}$ MEYER, Marshall. "Argentina Today”, 1982, Box 14.

${ }_{95}$ MEYER, Marshall. "Despedida de Bet El", 1984, Colección Audio, Archivo Marshall Meyer, Duke University Libraries.

${ }^{96}$ De su experiencia en Argentina derivó su prédica a favor de que, además de restar apoyo a regímenes como los de Pinochet en Chile o Stroessner en Paraguay, Estados Unidos "exportara la democracia", como diría al periodista Dennis Wholey en un programa televisivo. MEYER, Marshall. "Late Night America", programa de televisión emitido por KCET Channel Los Ángeles, 1985, Colección Audiovisual, Archivo Marshall Meyer, Duke University Libraries.
} 
labor religiosa se acompañó en muchas oportunidades de una misión autopercibida como civilizadora.

Como se ha visto, desde su llegada al país se formó una idea negativa del fenómeno peronista, en contra de cuyos principales referentes se manifestó en sermones y cartas. Todavía en 1986, en una de sus conferencias en Bet El, para transmitir que quería que la comunidad no confundiera su visita con una inspección caudillesca, dijo "no soy un tipo que vivía una vez en Puerta de Hierro y mandaba cassettes", aludiendo a los mensajes que Perón enviaba a sus simpatizantes durante sus años de exilio. ${ }^{97}$ Nunca estuvo más abiertamente opuesto a lo que, a sus ojos, este movimiento político encarnaba, que durante los años 1974 a 1976, un período que llegó a calificar como de "guerra civil". ${ }^{88} \mathrm{Al}$ deseo de un aliyah familiar, presente desde finales de los sesenta, sumó entonces un proyecto de aliyah colectivo, urgido por una situación política que consideraba desastrosa y amenazante para la vida judía. Ésta, más allá de cualquier coyuntura, no podía a su juicio ser nunca más plena que en Israel. Diez años después, en un contexto democrático, dijo a los socios de Bet El que "sería fabuloso pensar que todo el mundo se va a levantar y va a hacer aliyah". ${ }^{99}$ Aunque reconocía que eso "no va a pasar, por lo menos no pasó hasta ahora", se enorgullecía de que no hubiese otra sinagoga argentina con tantos ex socios viviendo en Israel.

El golpe de Estado de 1976 no lo sorprendió y generó en él, como en otros, la sensación de que el poder estatal se había recompuesto y de que la vida social comenzaba a ordenarse. Cuando advirtió que el Estado militar recurría a toda clase de violaciones a los derechos humanos asumió un abierto compromiso personal en su denuncia. A su misión religiosa - combatir la apatía y el desinterés en la vida judía y luchar contra la asimilación- unió una misión humanitaria que le valieron a él y a su familia amenazas periódicas, conflictos con las organizaciones oficiales del judaísmo e incomprensión en sus propias instituciones. Cuando Alfonsín lo condecoró con la Orden del Libertador General San Martín en el grado de Comendador, el máximo honor que otorga el Estado argentino, los nacionalistas de la revista Cabildo reflotaron las denuncias que había realizado $L a L u z$ a

\footnotetext{
${ }^{97}$ MEYER, Marshall. Tercera conferencia en su visita a la argentina de 1986, Box 9.

98 MEYER, Marshall. Conferencia "Why and How to Be An Activist", Dartmouth College, 17 de octubre de 1991, Colección Audiovisual, Archivo Marshall Meyer, Duke University Libraries.

${ }^{99}$ MEYER, Marshall. Tercera conferencia en su visita a la argentina de 1986, Box 9.
}

finales de los sesenta y, por lo mismo, el general Osiris Villegas demandó infructuósamente al presidente de la Nación y a su canciller, Dante Caputo, acusándolos de condecorar a un "extranjero indeseable". ${ }^{100}$

Exceptuando estos grupos minúsculos, hacia 1983 la figura de Meyer contaba con un reconocimiento que excedía el ámbito de los derechos humanos. El rabino Mario Ablin, miembro de la Israel Interfaith Association y vice-presidente de la Casa Argentina de Jerusalem, al enterarse de la designación de Meyer para integrar la CONADEP escribió que, a su juicio, era "el único representante de la comunidad judía organizada con derecho moral a llevar a cabo la tarea de esclarecer la suerte corrida por miles de víctimas sacrificadas por un régimen bárbaro ante el cual muchos permanecimos silenciosos". ${ }^{101}$ El propio Meyer no pensaba de un modo muy diferente. En una conferencia que pronunció en la Universidad Hebrea de Jerusalem, dos años antes de morir, manifestó que durante la dictadura argentina había habido solamente dos rabinos que se opusieron a la Junta Militar en materia de derechos humanos: él y Roberto Graetz, que integró la Asamblea Permanente de Derechos Humanos fundada unos meses antes del golpe de Estado de 1976. ${ }^{102}$

En los casi diez años que transcurrieron entre el regreso a los Estados Unidos y su muerte, Meyer sumó al reconocimiento del Estado argentino muchos otros, entre ellos el de Doctor Honoris Causa de la Universidad de Buenos Aires. El acto se realizó en 1993, pocos meses antes de morir. En esa oportunidad, el decano de la Facultad de Ciencias Sociales, Juan Carlos Portantiero, dijo que con esa distinción las autoridades universitarias buscaban honrar "al ciudadano universal de la causa más noble: la de la defensa de los derechos humanos". ${ }^{103} \mathrm{Al}$ concedérsele la palabra, Meyer volvió a leer el discurso que había pronunciado el 25 de abril de 1984 en la Plaza de la República, "Escoged, pues, la vida". Originalmente dirigido a una sociedad todavía no del todo consciente de la gravedad de lo que acababa de dejar atrás. Meyer consideraba aquel mensaje todavía actual.

\footnotetext{
100 "Osiris Villegas: Pide se procese a Alfonsín y Caputo por condecorar al rabino M. Meyer", La Prensa, 25 de septiembre de 1984. Sobre la revista Cabildo y su visión de los judíos, WAISMAN, 1987.

${ }^{101}$ ABLIN, Mario. Carta a Marshall Meyer, 25 de enero de 1984, Box 1.

${ }^{102}$ MEYER, Marshall. "Human Rights Violations in Argentina under Military Rule", Universidad Hebrea de Jerusalem, 21 de enero de 1992, Box 14. En agosto de 1980, el rabino Graetz dejó el país y se instaló en Río de Janeiro.

103 "Doctorado Honoris Causa UBA", agosto de 1993, Colección Audiovisual, Archivo Marshall Meyer, Duke University Libraries.
} 


\section{Referencias}

\section{Archivos consultados:}

Marshall T. Meyer Papers Collection, Human Rights Archive, David M. Rubenstein Rare Book \& Manuscript Library, Duke University.

Naomi Meyer, Colección personal, New York City, US.

Robert Cox, Colección personal, Charleston, Carolina del Sur, US.

Archivo Clarin, Buenos Aires, Argentina.

Hemeroteca de la Biblioteca de la Nación, Buenos Aires, Argentina.

\section{Bibliografía citada:}

ALTAMIRANO, Carlos. La pequeña burguesía, una clase en el purgatorio. En: Peronismo y cultura de izquierda. Buenos Aires: Siglo XXI, 2011.

CARASSAI, Sebastián. Antes de que anochezca: derechos humanos y clases medias en la Argentina antes y en los inicios del golpe de Estado de 1976. Prisma jurídico - Periódico em Filosofia e Teoria Geral do Direito, UNIVOVE, São Paulo, v. 8, n. 2, p. 337-362, 2009.

La violencia "de los dos lados". Hacia una genealogía de la teoría de los dos demonios (1969-1976). En: MIRA, Guillermo; PEDROSA, Fernando. Extendiendo los límites. Nuevas agendas en historia reciente. Buenos Aires: EUDEBA-Universidad Salamanca, 2016. p. 97-126.

COX, Robert. In Argentina, Alfonsín Becomes a "Strong Man" to Fight Conspiracy. Los Angeles Times, Nov. 11, 1985.

FAINSTEIN, Daniel. Rabino Marshall T. Meyer. Judaísmo, Direitos Humanos e Espiritualidade. Uma Biografia Intelectual. São Paulo: Comunidade Shalom, 2013.

FREED, Kenneth. For Argentine Jews, Survival Comes First. International Herald Tribune, Sept. 1, 1980.

KAHAN, Emmanuel. Recuerdos que mienten un poco. Vida y memoria de la experiencia judía durante la última dictadura militar. Buenos Aires: Prometeo, 2015.

LOTERSZTAIN, Gabriela. Los judios bajo el terror. Argentina 1976-1983. Buenos Aires: Ejercitar la memoria editores, 2008.

MEYER, Marshall. The Future of Latin American Jewry. En: World Council of Synagogues, Proceedings of Ninth International Convention. Jerusalem, Nov. 20-23, 1972.

El informe de las Fuerzas Armadas es un "Jilul Hashem" (Profanación de Dios). Mundo Israelita, 6 de mayo de 1983a.

Ensayo sobre judaísmo contemporáneo, antisionismo y antisemitismo. Rumbos, jul.-ago. 1983b.

Marshall Meyer, entrevista de Herman Schiller. En:

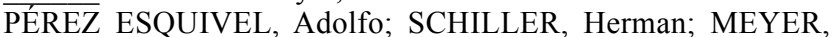
Marshall. Conferencias y reportajes sobre los Derechos Humanos en Argentina (1976-1983). Buenos Aires: Libreros y Editores del Polígono, 1983c. p. 49-50.
. El judaísmo y el cristianismo frente a la violencia estatal: el caso de Argentina, 1976-1983. En: SENKMAN, Leonardo; SZNAJDER, Mario. El legado del autoritarismo, derechos humanos y antisemitismo en Argentina. Buenos Aires: Grupo Editor Latinoamericano, 1995.

You Are My Witness: the Living Words of Rabbi Marshall T. Meyer. Editado por ISAY, Jane. New York: St. Martin's Press, 2004.

MOCHKOSFKY, Graciela. Timerman. El periodista que quiso ser parte del poder, 1923-1999. Buenos Aires: Editorial Sudamericana, 2004.

NOVARO, Marcos; PALERMO, Vicente. La dictadura militar (1976-1983): del golpe de Estado a la restauración democrática. Buenos Aires: Paidos, 2003.

PÉREZ ESQUIVEL, Adolfo. Reportaje exclusivo al Premio Nobel de la Paz 1980, arquitecto Adolfo Pérez Esquivel. Nueva Presencia, n. 172,17 oct. 1980 .

PLAVNIK, Baruj (Ed.). Marshall Meyer Antología. Buenos Aires: Comunidad Bet El, 1989.

REIN, Raanan; DAVIDI, Efraim. El caso Timerman, el establishment y la prensa israelí. Ciclos en la historia, la economía y la sociedad, Buenos Aires, v. 19, n. 38, dic. 2011.

ROSEMBERG, Diego. Marshall Meyer. El rabino que le vio la cara al diablo. Buenos Aires: Capital Intelectual, 2010.

SCHENQUER, Laura. Acomodamiento, aceptación, distanciamiento: las actitudes de la dirigencia judía frente a las autoridades del régimen militar. En: MIRA, Guillermo; PEDROSA, Fernando. Extendiendo los límites. Nuevas agendas en historia reciente. Buenos Aires: EUDEBA-Universidad Salamanca, 2016. p. 469-496.

SENKMAN, Leonardo (Ed.). El antisemitismo en la Argentina. Buenos Aires: Centro Editor de América Latina, 1986.

SENKMAN, Leonardo; SZNAJDER, Mario. El legado del autoritarismo, derechos humanos y antisemitismo en Argentina. Buenos Aires: Grupo Editor Latinoamericano, 1995.

SIGAL, Silvia. Intelectuales y poder en la década del sesenta. Buenos Aires: Punto Sur, 1991.

TERÁN, Oscar. Nuestros años sesentas. Buenos Aires: Punto Sur, 1991.

VOLCOVICH, Mariela. Marshall T. Meyer. Un hombre. El rabino. Buenos Aires: [S.n.], 2009.

WAISMAN, Carlos. Capitalism, Socialism, and the Jews: The View from Cabildo. En: ELKIN, Judith; MERKX, Gilbert (Ed.). The Jewish Presence in Latin America. Winchester, MA: Allen \& Unwin, 1987. p. 233-252.

ZOHAR, Marcel. Shlaj et amí lazalzel (Envía mi pueblo al demonio). Tel Aviv: Ediciones Tzitrin, 1991.

Recebido: 02 de septiembre de 2016 Aprovado: 19 de noviembre de 2016

\section{Autor/Author:}

SEBASTIÁN CARASSAI scarassai@conicet.gov.ar

- Profesor universitario (Universidad de Buenos Aires) e investigador adjunto en el Consejo de Investigaciones Científicas y Técnicas (CONICET), es licenciado en Sociología (UBA), magister en Sociología Económica (Universidad Nacional de General San Martín) y doctor en Historia (Universidad de Indiana). Ha publicado números capítulos de libros y artículos sobre historia reciente argentina e historia de las ideas, y los libros Los años setenta de la gente común. La naturalización de la violencia (Siglo XXI, 2013) y The Argentine Silent Majority. Middle Classes, Politics, Violence and Memory (Duke University Press, 2014), trabajo por el que recibió el Esther L. Kinsley Ph.D. Dissertation Award en 2012 y la mención honorable del Bolton-Johnson Prize en 2015 . En 2016 la Fundación Konex le otorgó el Diploma al Mérito en Humanidades. Actualmente trabaja como investigador en el National Humanities Center de los Estados Unidos, que en 2016 le concedió la Frank H. Kenan Fellowship para desarrollar el proyecto, Eclipsed Histories: The Sixties and Seventies in Argentina from a Microhistorical Perspective.

Professor Universidad de Buenos Aires and adjunct researcher in the Consejo de Investigaciones Científicas y Técnicas (CONICET), he holds a degree in Sociology (UBA), Masters in Economic Sociology (Universidad Nacional de General San Martín) and a PhD in History (Universidad de Indiana). He has published many chapters of books and articles about recent Argentinian history and the history of ideas, and the books Los años setenta de la gente común. La naturalización de la violencia (Siglo XXI, 2013) and The Argentine Silent Majority. Middle Classes, Politics, Violence and Memory (Duke University Press, 2014), for which he received the Estger L. Kinsley Ph.D. Dissertation Award in 2012 and honorific mention of the Bolton-Johnson Prize in 2015 . In 2016 the Fundación Konex granted him the Diplom al Mérito en Humanidades (Diploma of Merit in Humanities). Curently he works as a researcher at the National Humanities Center of the United States, which granted him the Frank H. Kenan Fellowship in 2016 to develop the project, Eclipsed Histories: The Sixties and Seventies in Argentina from a Microhistorical Perspective. 